\title{
Cochlear Implant Stimulation of a Hearing Ear Generates Separate Electrophonic and Electroneural Responses
}

\author{
Mika Sato, Peter Baumhoff, and Andrej Kral \\ Institute of AudioNeuroTechnology and Department of Experimental Otology, ENT Clinics, Hannover Medical School, 30625 Hannover, Germany
}

Electroacoustic stimulation in subjects with residual hearing is becoming more widely used in clinical practice. However, little is known about the properties of electrically induced responses in the hearing cochlea. In the present study, normal-hearing guinea pig cochleae underwent cochlear implantation through a cochleostomy without significant loss of hearing. Using recordings of unit activity in the midbrain, we were able to investigate the excitation patterns throughout the tonotopic field determined by acoustic stimulation. With the cochlear implant and the midbrain multielectrode arrays left in place, the ears were pharmacologically deafened and electrical stimulation was repeated in the deafened condition. The results demonstrate that, in addition to direct neuronal (electroneuronal) stimulation, in the hearing cochlea excitation of the hair cells occurs ("electrophonic responses") at the cochlear site corresponding to the dominant temporal frequency components of the electrical stimulus, provided these are $<12 \mathrm{kHz}$. The slope of the rate-level functions of the neurons in the deafened condition was steeper and the firing rate was higher than in the hearing condition at those sites that were activated in the two conditions. Finally, in a monopolar stimulation configuration, the differences between hearing status conditions were smaller than in the narrower (bipolar) configurations.

Key words: cochlear implants; electroacoustic stimulation; electroneural stimulation; electrophony

\section{Significance Statement}

Stimulation with cochlear implants and hearing aids is becoming more widely clinically used in subjects with residual hearing. The neurophysiological characteristics underlying electroacoustic stimulation and the mechanism of its benefit remain unclear. The present study directly demonstrates that cochlear implantation does not interfere with the normal mechanical and physiological function of the cochlea. For the first time, it double-dissociates the electrical responses of hair cells (electrophonic responses) from responses of the auditory nerve fibers (electroneural responses), with separate excited cochlear locations in the same animals. We describe the condition in which these two responses spatially overlap. Finally, the study implicates that using the clinical characteristics of stimulation makes electrophonic responses unlikely in implanted subjects.

\section{Introduction}

The cochlear implant is the most successful neuroprosthetic device, and is becoming more widely used to restore hearing. The clinical criteria for cochlear implantation have recently changed from profound deafness to the presence of significant residual

\footnotetext{
Received Aug. 5, 2015; revised 0ct. 12, 2015; accepted Nov. 9, 2015.

Author contributions: M.S. and A.K. designed research; M.S. and P.B. performed research; M.S. and A.K. analyzed data; M.S., P.B., and A.K. wrote the paper.

This work was supported by the German Research Foundation (Deutsche Forschungsgemeinschaft; Cluster of Excellence Hearing4all) and MED-EL GmbH, Innsbruck, Austria.

The authors declare no competing financial interests.

This article is freely available online through the J Neurosci Author Open Choice option.

Correspondence should be addressed to Dr. Mika Sato, Institute of AudioNeuroTechnology and Department of

Experimental Otology, Hannover Medical School, Feodor-Lynen-Strasse 35, 30625 Hannover, Germany. E-mail: sato.mika@mh-hannover.de.

DOI:10.1523/JNEUROSCI.2968-15.2016

Copyright $\odot 2016$ Sato et al.

This is an Open Access article distributed under the terms of the Creative Commons Attribution License Creative Commons Attribution 4.0 International, which permits unrestricted use, distribution and reproduction in any medium provided that the original work is properly attributed.
}

hearing (James et al., 2005; Kiefer et al., 2005; Fraysse et al., 2006; von Ilberg et al., 2011). More detailed knowledge of cochlear anatomy (Erixon et al., 2009; Biedron et al., 2010; Erixon and Rask-Andersen, 2013; Avci et al., 2014) has resulted in increasing preservation of residual hearing, as has further development of cochlear implants and surgical techniques (McAnally et al., 1997c; Lenarz et al., 2009; Skarzynski and Lorens, 2010). In affected subjects, electrical stimulation of auditory nerve fibers via the implant, combined with acoustic stimulation of the hair cells by means of a hearing aid, delivers significant improvements in speech understanding, particularly in demanding conditions (Gstoettner et al., 2004; Lenarz et al., 2009; Wilson, 2010; Zhang et al., 2010).

Electrical stimulation of the deaf cochlea activates the auditory nerve fibers directly and generates "electroneural" $(\alpha)$ responses characterized by short latency, a high level of synchronization, recruitment of many nerve fibers, and a small dynamic range (Hartmann et al., 1984; Kral et al., 1998). Electrical stimulation of a residually hearing cochlea may additionally result in what are known as electrophonic $(\beta$ and $\delta$ ) responses character- 
ized by longer latencies and larger dynamic range (van den Honert and Stypulkowski, 1984; Miller et al., 2006, 2008). These responses are most likely based on indirect effects caused by basilar membrane movement due to electrical fields, but potentially also involve direct stimulation of hair cells (van den Honert and Stypulkowski, 1984). Compound action potential recordings following electrical stimulation suggest that the electrophonic response is related to the temporal characteristics of the time function of the electrical stimulus (McAnally et al., 1997a,c). Sinusoidal stimulation of cochleae with residual hearing may indeed result in a decrease in threshold for fibers with characteristic frequency close to the stimulus frequency (Moxon, 1971). It has recently been shown that electrical and acoustic responses in a cochlea with residual hearing interact, and that the majority of these interactions involve mild suppression without significant distortions (Tillein et al., 2015). Masking phenomena between acoustic and electrical stimulation are, therefore, known; however, the proportion of electrophonic and electroneural components with electrical stimulation, the site of their generation, and their overlap remain unclear.

There are also discrepant data on the properties of electrophonic responses. For fibers demonstrating both $\alpha$ and $\beta$ responses, the $\beta$ (electrophonic) responses occurred at lower current levels than the direct electroneural $\alpha$ responses (van den Honert and Stypulkowski, 1984; Lusted and Simmons, 1988; Miller et al., 2006, 2008). At higher current levels, both electroneural and electrophonic responses were observed. However, some studies have reported that electrical stimulation thresholds are lower in deaf cochleae (Yamane et al., 1981; Miller et al., 2006). All of these findings were based either on a small sample of recorded single auditory nerve fibers or on population measures such as compound action potentials. Previous studies were unable to resolve the discrepancies, partly because intracochlear stimulation was associated with significant and variable hearing impairment.

In the present study, normal-hearing cochleae were stimulated with a cochlear implant. Using multielectrode arrays, we recorded activity from all regions of tonotopic representation in the auditory midbrain at the same time. The responses were compared with those obtained after deafening the cochleae in the same animals, with the implant kept in place. The present study for the first time demonstrates that cochlear implantation with minimal hearing loss is possible, and that (depending on the details of the stimulation) the electrophonic and electroneural responses take place at two separate cochlear partitions related to the properties of the stimulation.

\section{Materials and Methods}

Eleven adult Dunkin-Hartley guinea pigs (Charles River) of either sex were used for the present study. All experimental procedures were approved by the local state authorities and were performed in compliance with the guidelines of the European Community for the care and use of laboratory animals (EU VD 86/609/EEC) and the German Animal Welfare Act (TierSchG).

The animals were premedicated by peroral administration of $1.5 \mathrm{mg}$ of diazepam (Ratiopharm $\mathrm{GmbH}$ ). Anesthesia was administered by intramuscular injection of $50 \mathrm{mg} / \mathrm{kg} 2 \%$ ketamine solution (CP Pharma) and $10 \mathrm{mg} / \mathrm{kg} \mathrm{10 \%}$ xylazine solution (WDT), volume-adjusted to the animals' body weight. Maintenance doses were $12-15 \mathrm{mg} / \mathrm{kg}$ ketamine and $2.5-3.0 \mathrm{mg} / \mathrm{kg}$ xylazine. The initial anesthesia dose contained $0.1 \mathrm{mg} / \mathrm{kg}$ atropine sulfate (B. Braun) to prevent mucous obstruction of airways during surgery. The animals were tracheotomized and artificially ventilated using a rodent ventilator (Ugo Basile). The end-tidal $\mathrm{CO}_{2}$ concentration was kept below $4 \%$. The core temperature of the animals was monitored and controlled and kept above $38^{\circ} \mathrm{C}$ using a homeothermic blanket (TC-1000 Temperature Controller, CWE Inc.) at $37^{\circ} \mathrm{C}$ throughout the experiment. Heart rate, ventilation rate, and end-tidal $\mathrm{CO}_{2}$ were used to monitor physiological activity. Additionally, the paw-pinch withdrawal reflex was tested at regular intervals to verify anesthesia depth. For fluid replacement, 3-6 $\mathrm{ml}$ of Ringer's solution was subcutaneously applied every $2.5-5.0 \mathrm{~h}$.

Auditory brainstem-evoked responses (ABRs) to condensation clicks (50 $\mu \mathrm{s})$ applied by means of a calibrated DT48 speaker (Beyerdynamic) in open field were recorded using a subcutaneous $\mathrm{Ag} / \mathrm{AgCl}$ electrode at the vertex at the interauricular line. A reference was placed retroauricularly ( $\mathrm{Ag} / \mathrm{AgCl}$ electrode) on each side. The recorded signal was amplified $(100 \mathrm{~dB})$ and filtered (Butterworth filter, sixth order, $200 \mathrm{~Hz}-5 \mathrm{kHz})$, presented at sound-pressure levels of $0-90 \mathrm{~dB}$ SPL 100 times at a repetition rate of $30 \mathrm{~Hz}$, and averaged.

Animal heads were subsequently secured in a customized rodent snout holder that allowed adjustment of the head position along three axes. Following retroauricular incision, the tympanic bulla was exposed and carefully opened with a fine needle. The opening was widened using a micro-rongeur to obtain access to the round window niche (Fig. $1 A$ ). Afterward, cochleostomy was performed (Fig. 2A) using a drill (NSK Ultimate XL) at a very slow speed $(<4000 / \mathrm{min})$. Consequently, ABR threshold measurement confirmed the absence of significant hearing loss due to cochleostomy. All animals used in the present study had ABR thresholds $<30 \mathrm{~dB} \mathrm{SPL}_{\mathrm{pe}}$ as measured post- cochleostomy.

The head was then additionally secured in the stereotactic frame using ear bars and bone screws that were secured using dental acrylic. After the head was firmly fixed in place in the stereotactic frame, a trephination was performed and the dura mater beneath it was carefully removed. The ear bars were then removed and the multielectrode array (NeuroNexus Technologies; double-shank 32 sites, impedance 1-2 $\mathrm{m} \Omega$, intersite distance $100 \mu \mathrm{m}$, distance between shanks $500 \mu \mathrm{m}$ ) was inserted at an angle of $45^{\circ}$ into the inferior colliculus by stereotactic penetration using a mechanical micromanipulator (TSE). The cortex was covered with medical-grade silicone oil to prevent evaporation from the exposed surface of the cortex. A recording $\mathrm{Ag} / \mathrm{AgCl}$ reference electrode was placed epidurally at the lambda point.

Acoustic stimuli were generated in a randomized fashion using AudiologyLab 24 (Otoconsult). Recorded signals were amplified (Neuralynx Cheetah 64-channel amplifier, amplification 10,000 times, filter $1 \mathrm{~Hz}-9$ $\mathrm{kHz}$ ) and stored using a 32-channel MIO card (NI-6259 National Instruments, Austin) using AudiologyLab 24 (Otoconsult). Correct placement of the recording multielectrode array was confirmed by receptive-field measurement (tones, frequencies $500 \mathrm{~Hz}-32 \mathrm{kHz}$, five steps per octave, 0-90 dB SPL, $5 \mathrm{~ms}$ on/off flanks, $50 \mathrm{~ms}$ duration) using a calibrated DT48 speaker (Beyerdynamic, driven by an Otoconsult AMP70 amplifier; calibration using a Bruel \& Kjaer 1/4 inch microphone type 4939, a Falcon preamplifier type 2670, and a Bruel \& Kjaer Nexus 2690 amplifier) in open field at a repetition rate of five stimuli per second. For receptive field mapping, 10 responses were averaged. The outcome of the mapping procedure was information on the characteristic frequency $(\mathrm{CF})$ of each site (Fig. 1C). The sharp tuning, short latencies, and homogeneous inclusion of the CFs from $\sim 1$ to $32 \mathrm{kHz}$ allowed us to functionally confirm placement in the central nucleus of the inferior colliculus.

A guinea pig cochlear implant (four contacts spaced $1 \mathrm{~mm}$ apart, MED-EL GmbH) was subsequently inserted into the cochlea through the cochleostomy. Great care was taken to prevent any mechanical damage: penetration was stopped after the last contact and the black mark $1 \mathrm{~mm}$ after the basal-most contact (Fig. 1B) had been inserted into the cochlea up to the point where the black mark was on the edge of the cochleostomy. It was held under the direct view. No resistance was felt during insertion. The electrode was fixed with surgical glue (Histoacryl, Braun Aesculap AG) on the bony edge of the opened bulla. The receptive fields were re-measured to ensure there was no significant cochlear damage.

Subsequently, electrical stimulation by means of the cochlear implant was applied via optically coupled current sources (ICS 10, Otoconsult). All stimuli were charge-balanced and included biphasic pulses (100 $\mu \mathrm{s} /$ phase) and sinusoidal stimuli (3 ms duration, $1 \mathrm{~ms}$ rise/fall), with current level controlled using attenuators (ATT15, Otoconsult). Electrode 1 was 
the apical-most contact of the implant and electrode 4 the basal-most contact. Different bipolar $(1 / 2,2 / 3,3 / 4$ and $1 / 3,1 / 4,2 / 4)$ and monopolar configurations (1/Ind., $2 /$ Ind., 3/Ind., 4/Ind.; Ind., indifferent extracochlear electrode) were used for stimulation. The indifferent (return) electrode for monopolar stimulation was placed retroauricularly. After this procedure, the acoustic receptive fields were re-measured (Fig. 2) to ensure that hearing was preserved throughout the electrical stimulation procedure.

Finally, hearing was destroyed by a very slow intracochlear application of $100 \mu \mathrm{l}$ of $5 \%$ neomycin sulfate solution (Caesar \& Lorentz $\mathrm{GmbH}$ ) through the cochleostomy using a fine injection needle ( $27 \mathrm{G}, 0.4 \mathrm{~mm}$ diameter) bent $\sim 20^{\circ}$ to keep the view to the tip on application. This procedure was performed without displacing the cochlear implant. The neomycin was rinsed with Ringer's solution (BerlinChemie AG) after the severe hearing loss (threshold $>70 \mathrm{~dB}$ at most of the frequency) was observed on the microelectrode array with the stimuli used previously for the receptivefield mapping. The same electrical stimulation was applied in the deafened condition.

The recorded data were analyzed offline. First, the matrix of the recorded signals was filtered for unit activity (high-pass secondorder elliptic filter, cutoff frequency $400 \mathrm{~Hz}$ ). A threshold value for triggering action potentials was selected as exceeding 3 SDs above noise level and as time duration above threshold exceeding $0.25 \mathrm{~ms}$. The peak-to-peak noise level with the used amplifier was in the range of $\pm 15 \mu \mathrm{V}$.

For responsiveness, the peristimulus time histograms with $1 \mathrm{~ms}$ bins obtained from 10 (acoustic) or 50 (electrical) stimulus repetitions were compared, and the firing rate was expressed as the maximum instantaneous multiunit firing rate per millisecond within the response in the peristimulus time histogram. Due to the low spontaneous rates at some sites, the threshold for responsiveness could not be reliably calculated relative to baseline. Instead, the maximum firing rate was used as a reference. Rate-level functions were determined for each site and for threshold values. These were first automatically defined as current levels for which the responses exceeded $12 \%$ of the maximum firing rate for the entire excitation profile recorded by the probe, regardless of the site where it was found. The sites were then classified as responding only if (from threshold level) the firing rate kept increasing with increasing current level; it had to exceed the threshold at a minimum of two subsequent levels. All results were subsequently manually checked for consistency between animals. From responding sites, thresholds, tuning curves (acoustic and spatial electric), and rate-level functions were determined and compared.

Statistical comparisons were performed using the nonparametric Wilcoxon-Mann-Whitney two-tailed test, with a significance level of 5\%.

\section{Results}

The hearing thresholds of all investigated animals were first screened by click-evoked brainstem responses. Only normalhearing animals (with hearing thresholds $<30 \mathrm{~dB}$ SPL) were used in the present study. After surgically exposing the cochlea, a cochleostomy was carefully drilled into the scala tympani close to the round window (Fig. 2A). The cortex overlying the inferior colliculus was exposed, and single- or double-shank electrode arrays with 16 contacts per shank were inserted stereotactically into the inferior colliculus. Using acoustic stimulation, receptive fields were determined for unit responses at each electrode site (Fig. 1C). Characteristic frequencies (CFs), defined as those stimulus frequencies for which the individual units had lowest thresholds, were subsequently used to align data from all animals (Fig. $1 C)$.

A guinea pig cochlear implant was inserted through the cochleostomy. Great care was taken to avoid any contact with structures within the scala tympani. The effect of implantation on hearing thresholds was verified by re-measuring the receptive fields using the multielectrode array in the inferior colliculus. Lowest response thresholds for each tested stimulus frequency were determined for each animal and were used to construct inferior colliculus audiograms (Fig. 2B). It must be borne in mind that these audiograms do not represent the hearing thresholds of the animal, but rather the combination of hearing thresholds and the sampling of the tonotopic array using the multielectrode array in the inferior colliculus. The thresholds in Figure $2 B$ were the lowest response threshold obtained in the inferior colliculus regardless of the CF of the recording site; thus, the abscissa reflects the stimulation parameters, not the recorded CFs, and the ordinate the lowest threshold observed at any site of the recording multielectrode array. On average, our cochlear implantation caused only modest changes $(<30 \mathrm{~dB})$ in such thresholds. Shifts in CFs were not observed. This convincingly demonstrates that cochlear implantation is not acutely harmful for normal hearing 
A
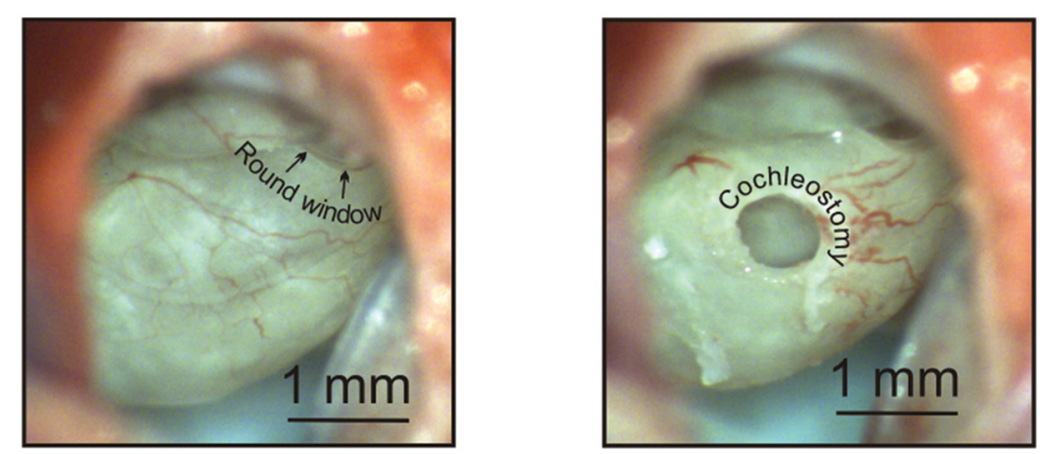

B

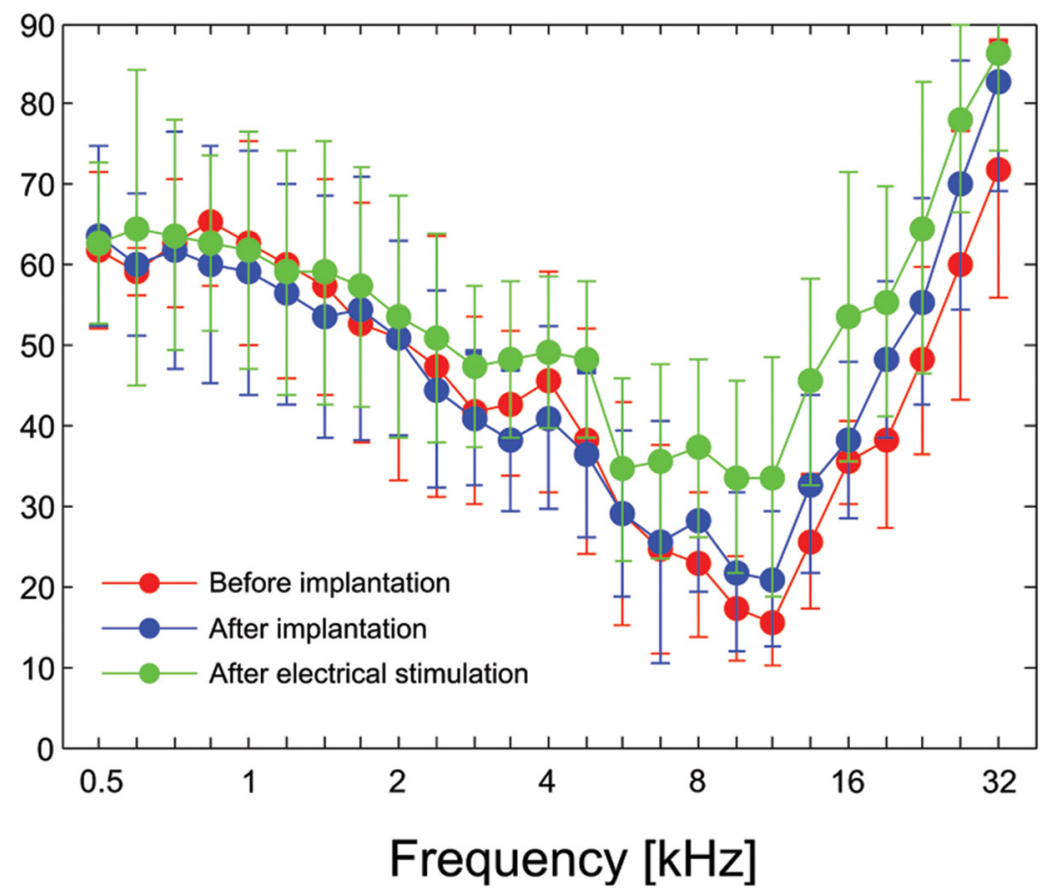

Figure 2. Cochlear implantation in the guinea pig. $\boldsymbol{A}$, Left, Round window niche and the view of the cochlea through the cochleostomy. Right, Position of the cochleostomy. $\boldsymbol{B}$, Hearing thresholds defined as the lowest threshold determined at each tested frequency by the multielectrode array placed in the inferior colliculus. The data shown are means \pm SD from all animals ( $n=11)$. Red, Thresholds before implantation. Blue, Thresholds after implantation. Green, Thresholds after electrical stimulation (before pharmacological deafening).

and for the relevant cochlear mechanics, provided implantation damage is avoided.

Next, electrical stimulation was performed via the cochlear implant and the midbrain responses were recorded. After several hours of experimentation in the hearing condition, the hearing thresholds were reassessed by the same procedure. The mean hearing loss at the end of the experiments was only mild $(<20 \mathrm{~dB}$ compared with the condition after implantation; Fig. $2 B$ ), and the loss occurred only for the basal part of the cochlea. The cause of the modest increase in hearing thresholds is unclear. One potential reason is that of delayed effects of cochleostomy and implantation, including inflammatory processes triggered by the procedure.

Electrical stimulation was performed using different monopolar and bipolar configurations and, as far as possible, all intracochlear electrodes were used. Excitation profiles in the central nucleus of the inferior colliculus were registered. In bipolar stimulation of hearing cochleae (Fig. 3A, left panels), lowest thresholds for electrical stimulation were observed at sites with CFs of 3-6 kHz (Fig. 3A, asterisks), regardless of the contact used for stimulation. This threshold was lowest for most apical stimulation contacts $(1 / 2)$ and successively increased with basal shift of the stimulation electrodes. Furthermore, another focus of activity was observed in the neurons with high CFs; here, the most strongly excited site (Fig. $3 A$, arrow) moved basally when the stimulation was shifted to more basal contacts. Interestingly, the evoked firing rates were consistently higher at the basal spot than at the apical one. These two spots of excitation-one sensitive to the position of the stimulating contact, and the other insensitive-were consistently observed in all investigated animals.

To further differentiate the two types of responses, we deafened the cochleae using slow intracochlear instillation of 5\% neomycin with the cochlear implant left in place. After a severe hearing loss was observed, the neomycin was washed out using Ringer's solution. Acoustic stimulation demonstrated the acoustic threshold above $60 \mathrm{~dB}$ in the inferior colliculus for all frequencies previously used to map the receptive fields, and $70 \mathrm{~dB}$ for frequencies above $3 \mathrm{kHz}$ in most of the animals. In one animal, residual hearing extended to the 5 $\mathrm{kHz}$ region, with acoustic hearing threshold of $60 \mathrm{~dB}$ SPL. This animal showed results consistent with all other animals and therefore was not excluded from the study. Subsequently, the same electrical stimulation was performed using the cochlear implant in the deafened condition.

The excitation profiles showed stronger post-deafening responses (i.e., higher firing rates) throughout the entire cochlea, but with higher thresholds, particularly for the most apical stimulation electrodes 1/2 (Fig. $3 A$, right panels). Furthermore, the low-threshold peak in the $\sim 5 \mathrm{kHz}$ CF region disappeared after deafening. The regions showing lowest thresholds were now at positions that previously had acoustic receptive fields with $\mathrm{CFs}>9 \mathrm{kHz}$. Where more basal contacts were used for stimulation, the best threshold position was observed at higher CF positions: in the example shown, best responses were at $9.5 \mathrm{kHz}$ for electrodes $1 / 2$, at $11.3 \mathrm{kHz}$ for $2 / 3$, and at $13.5 \mathrm{kHz}$ for $3 / 4$. This would approximately correspond to the location of the apical contact of the pair of electrodes used for stimulation. Thresholds in both groups of animals increased with basal shift of the stimulation electrodes. Such increases in threshold with basal shift of the stimulation in the deaf condition are a known consequence of the larger diameter of the scala tympani and, thus, due to greater current shunt and the greater distance to the auditory nerve (Kral et al., 1998).

The low-threshold spot at a CF close to $5 \mathrm{kHz}$ was observed only in hearing cochleae. The $5 \mathrm{kHz}$ corresponds to the dominant frequency component of a $100 \mu \mathrm{s} /$ phase biphasic pulse. The effect of deafening suggests that this response is electrophonic in nature, caused by excitation of hair cells. The other excitation 
A
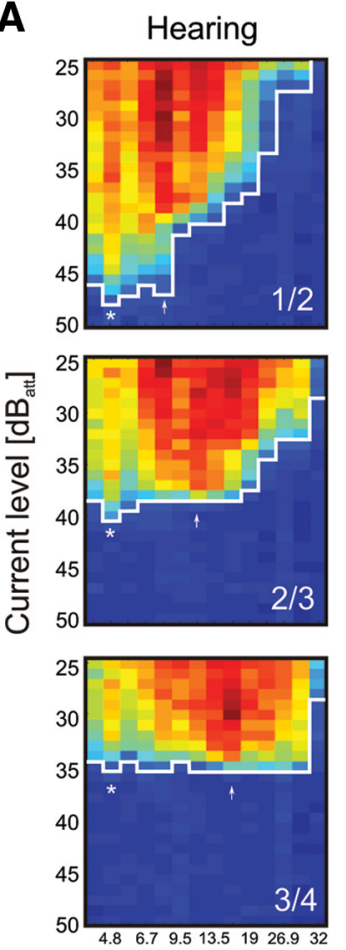

Deaf
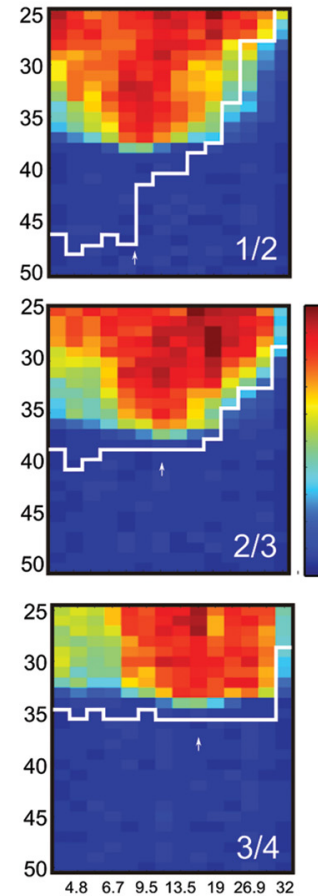

B

Hearing, $\mathrm{CF} \leq 9 \mathrm{kHz}$ Deaf, $\mathrm{CF} \leq 9 \mathrm{kHz}$
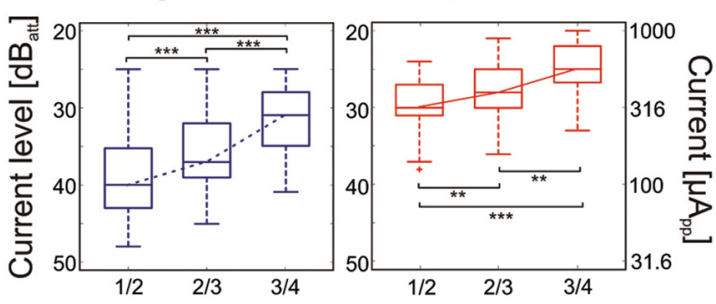

Stimulation configuration (electrodes)

\section{C}

Hearing, $\mathrm{CF}>9 \mathrm{kHz}$ Deaf, CF $>9 \mathrm{kHz}$

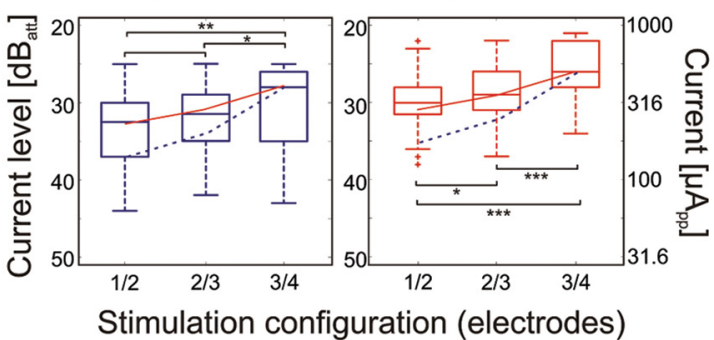

Site's characteristic frequency [kHz]

Figure 3. Effects of electrode position in the cochlea, biphasic pulse (100 $\mu \mathrm{s} /$ phase). $A$, Excitation profiles (spatial tuning curves) obtained for different narrow bipolar configurations in hearing (left) and deafened (right) cochlea in an example animal. White line shows the threshold in the hearing condition. Asterisk and arrow indicate sites with low thresholds. Changing the position of the active electrodes affected only the (F for the more basal low-threshold site (arrow); the more apical low-threshold site (asterisk) did not change. Deafening resulted in loss of the very sensitive low-CF responses (asterisk) at $4.6 \mathrm{kHz}$, but the basal response remained discernible and changed corresponding to the position of the active electrodes in the cochlea. $\boldsymbol{B}$, Effects of stimulation configuration on thresholds in all 11 animals for low-CF sites (apical cochlea) in hearing (blue) and deafened (red) condition. The thresholds increased with basal shift of the active electrodes in both hearing and deafened conditions, but the effect was stronger for the hearing condition. C, Same data for high-CF sites (i.e., basal cochlea). For comparisons, the blue dashed curve represents the change in median threshold with position for the hearing condition in $\boldsymbol{B}$, and the red line shows the same for the deaf condition in $\boldsymbol{B}$. In the basal cochlea, the change of thresholds with cochlear position of the active electrode differs from the hearing condition in $\boldsymbol{B}$, regardless of the hearing status. $40 \mathrm{~dB}_{\text {att }}$ correspond to $100 \mu \mathrm{A}_{\mathrm{pp}}$. Two-tailed Wilcoxon-Mann-Whitney test, ${ }^{*} \sim 5 \%$ significance level; ${ }^{* *} \sim 1 \%$ significance level; ${ }^{* * *} \sim 0.1 \%$ significance level.

spot at $\mathrm{CFs}>9 \mathrm{kHz}$, preserved after deafening and systematically dependent on the cochlear location of the active electrodes, represents an electroneural response caused by direct stimulation of the spiral ganglion cells.

To further investigate this hypothesis, data were considered separately for cochlear regions where the implant was located and those that were beyond the direct influence of the implant. For these purposes, reference was made to the length of the electrode array, to previous studies from our laboratories in which the position of cochlear implants were reconstructed histologically using the grinding technique (Burghard et al., 2014), and to the frequency map of the cochlea (Greenwood, 1990; Tsuji and Liberman, 1997). Since we sought to prevent any implantation trauma due to the implantation depth used, the implant could not pass the $180^{\circ}$ cochlear position. This implies that the implant did not penetrate apically from the $9 \mathrm{kHz}$ position. The cochleostomy was slightly apical to the $32 \mathrm{kHz}$ position. We therefore decided to pool data separately from positions with $\mathrm{CFs} \leq 9 \mathrm{kHz}$ (apical cochlea) and $>9 \mathrm{kHz}$ (basal cochlea). This allowed us to investigate the presumed electrophonic response (at sites with CFs $\leq 9 \mathrm{kHz}$ ) separately from the presumed electroneural component $(\mathrm{CF}>9 \mathrm{kHz})$.

When different stimulation configurations were statistically compared in the hearing and deafened condition, and separately for sites with $\mathrm{CF} \leq 9 \mathrm{kHz}$ and $\mathrm{CF}>9 \mathrm{kHz}$, interesting observations were made corresponding to the single case presented in
Figure $3 A$. The cochlear location of the active electrode caused the lowest threshold for electrodes $1 / 2$, followed by $2 / 3$ and $3 / 4$ in the hearing condition and $\mathrm{CFs} \leq 9 \mathrm{kHz}$ (Fig. 3B). The steep change in thresholds with basal shift of active electrodes was observed only in the hearing condition. In the deaf condition at CFs $\leq 9 \mathrm{kHz}$ (Fig. $3 B$, right panel), and in both hearing and deaf conditions at $\mathrm{CF}>9 \mathrm{kHz}$ (Fig. $3 \mathrm{C}$ ), the increase in threshold with a basal shift of active electrodes was very similar and much shallower than in the apical hearing cochlea. The implication of this result is that the cochlear stimulation site did affect the threshold most in the apical cochlea in the hearing condition. The critical distance of the source of the electrical field to the position generating a strong electrophonic response (in the hearing condition) appeared to be more than an octave, as the $5 \mathrm{kHz}$ low-threshold response was observed in electrodes $1 / 2$ (electroneural spot near $9.5 \mathrm{kHz}$ ) and partially in $2 / 3$ (electroneural spot near $11.3 \mathrm{kHz}$ ), but much less so with electrodes $3 / 4$ (located near $\mathrm{CF}=13.5$ $\mathrm{kHz})$.

Furthermore, we investigated how the spread of excitation (a change from narrow bipolar to broad bipolar and monopolar) affects the two different responses. In the hearing condition, increasing the spread of excitation mainly affected the electroneural threshold $(\mathrm{CFs}>9 \mathrm{kHz}$ ), whereas the electrophonic response was less affected (another individual example is shown in Fig. 4). Rate-level functions are often used to compare the electrophonic and electroneural responses, with electroneural responses having 
A

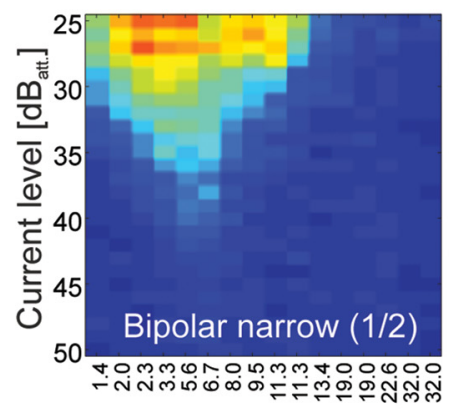

B

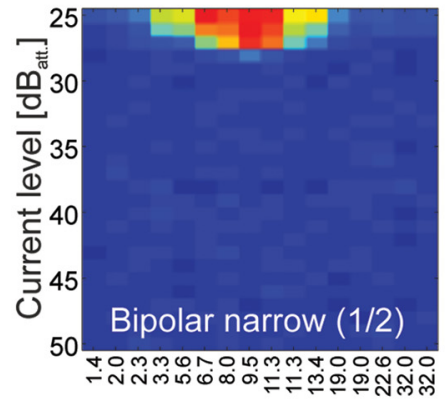

C

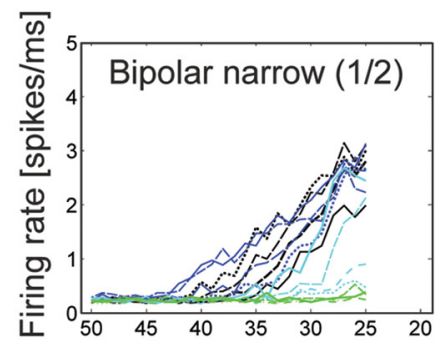

D

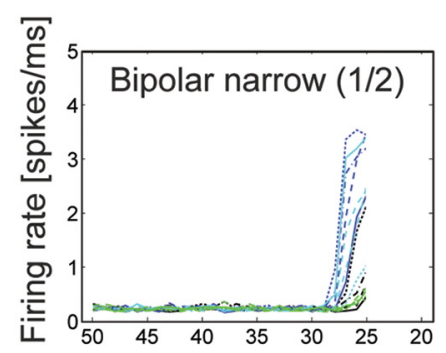

Hearing condition

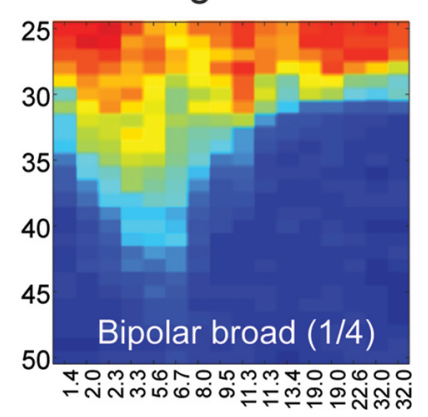

Site's characteristic frequency [kHz]

\section{Deafened condition}
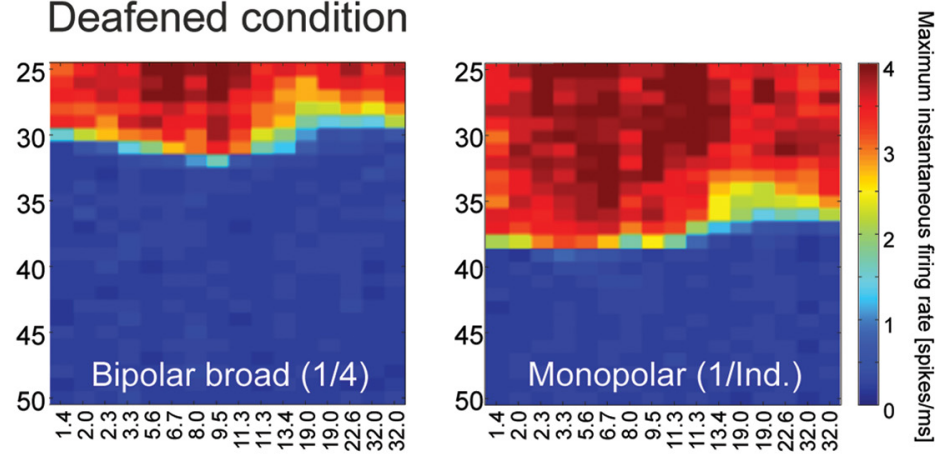

Site's characteristic frequency $[\mathrm{kHz}]$

\section{Hearing condition}

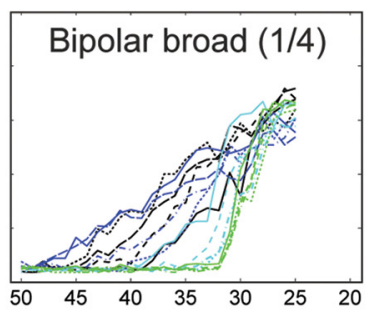

Deafened condition

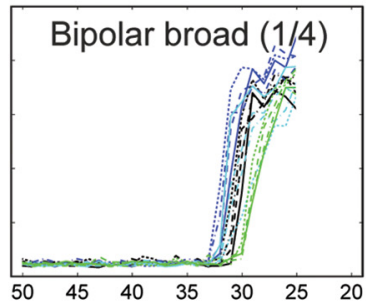

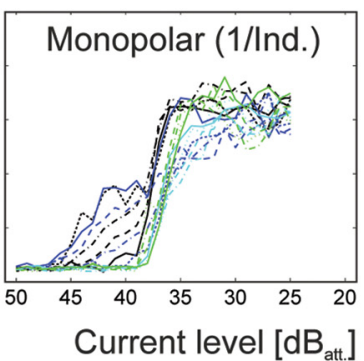

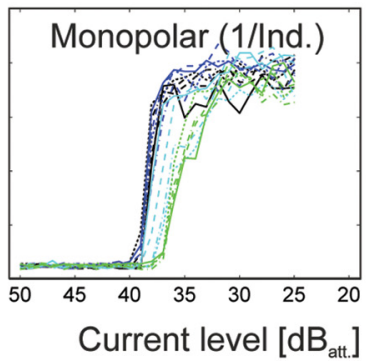

Figure 4. Effect of the spread of the electrical field, biphasic pulse (100 $\mu \mathrm{s} / \mathrm{phase}) . \boldsymbol{A}$, Example of excitation profiles for one hearing animal. The site's (F with lowest threshold (5.6 kHz) remained unaffected by the increase in spread of the electrical field. $\boldsymbol{B}$, Data from the same animal after deafening. The low-threshold peak disappeared. $\boldsymbol{C}$, Rate-level functions for the data in $\boldsymbol{A}$. The site's $\mathrm{CF}$ is designated by color, starting with black (lowest CFs), blue (mid CFs) and green (high (Fs). Sites with low CF show shallow rate-level functions. $\boldsymbol{D}$, After deafening, shallow rate-level functions disappeared and thresholds increased. $40 \mathrm{~dB}_{\text {att }}$ correspond to $100 \mu \mathrm{A}_{\mathrm{pp}}$.

a smaller dynamic range. In the hearing, electrically stimulated cochleae, rate-level functions of two types were indeed observed (Fig. 4C): some had a shallow slope and low thresholds and were typically found at recording sites with low CFs $(\leq 9 \mathrm{kHz})$, and others showed steeply increasing rate-level functions found in units with high CFs $(>9 \mathrm{kHz})$. In the same ear in the deafened condition, only the steep functions were observed throughout the entire cochlea (Fig. 4D). In consequence, the low-threshold region (black and dark blue colors in Fig. $4 C, D$ ) corresponded to the shallow rate-level functions in the hearing condition, and the other regions corresponded to the steep rate-level functions. In the basal cochlear partition only the steep rate-level functions 
were observed both in hearing and deafened conditions (green color in Fig. $4 C, D)$.

Next, thresholds for the presumed electrophonic response were pooled and compared among these three different configurations. The presumed electrophonic response at low CFs, evaluated in the hearing condition, had similar thresholds in all configurations (Fig. 5A, blue color), whereas the presumed electroneural threshold, evaluated in the deafened condition, decreased steeply with increasing spread of excitation (Fig. $5 A, B$, red color). This further supports a genuine difference in the mechanism of excitation in the hearing and deafened condition. The response in the hearing basal cochlea (Fig. 5B) was more similar to the response in the deaf than to the hearing apical cochlear response.

To investigate the rate-level relations at the population level, all rate-level functions from all 11 animals are presented in Figure 5, $C-H$. Rate-level functions were constructed for all recording sites in the $<9 \mathrm{kHz}$ and $\geq 9 \mathrm{kHz}$ groups in all stimulation configurations of electrode 1 (narrow bipolar, wide bipolar, monopolar; Fig. 5). In all these conditions, the evoked firing rates were significantly higher in the deafened condition than in the hearing condition at all levels above threshold (two-tailed Wilcoxon-Mann-Whitney test, $\alpha=5 \%$ ). Only in monopolar conditions at sites with $\mathrm{CF}>9 \mathrm{kHz}$ was the difference smaller (yet statistically significant). These data show that responsiveness to electrical stimulation, when quantified by the evoked firing rate, is in principle higher in deafened cochleae.

Furthermore, the rate-level functions in the apical cochlea were-for all configurations tested-steeper in the deafened condition than in the hearing condition (Fig. $5 C, E, G$ ). In the basal cochlea, the rate-level functions were similarly steep in the hearing and deafened conditions (Fig. $5 D, F, H$ ), indicating the predominance of electroneural stimulation in both conditions in the basal high-CF regions of the cochlea.

These characteristics of the responses again support the suggestion that the lowthreshold weak-response type in the lowfrequency region is due to electrophonic stimulation. In the hearing condition, as in the example shown in Figure $6 A$, the majority of the comparisons in the $0-9 \mathrm{kHz}$ region had significantly lower stimulation thresholds than in the deaf condition. In the region above $9 \mathrm{kHz}$, the differences were smaller. To analyze this observation in more
A $\quad \mathrm{CF} \leq 9 \mathrm{kHz}$
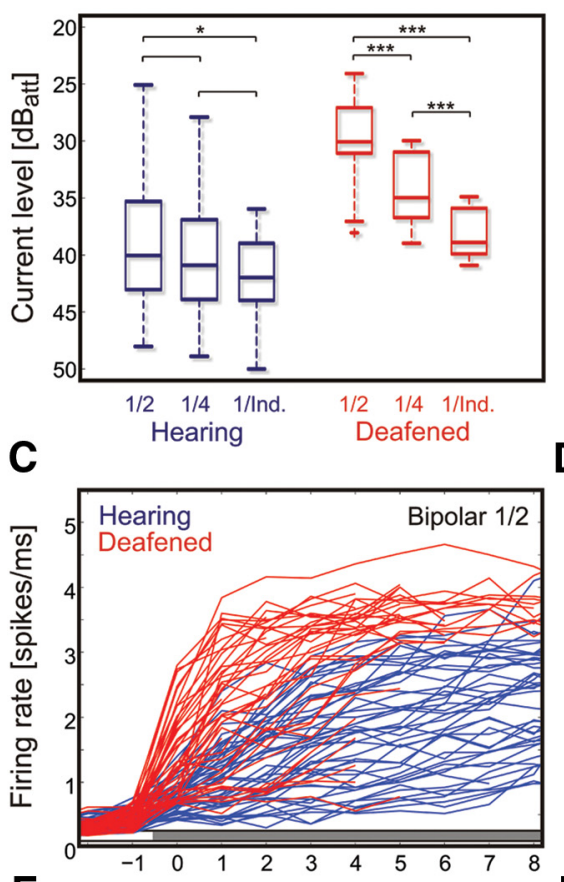

E
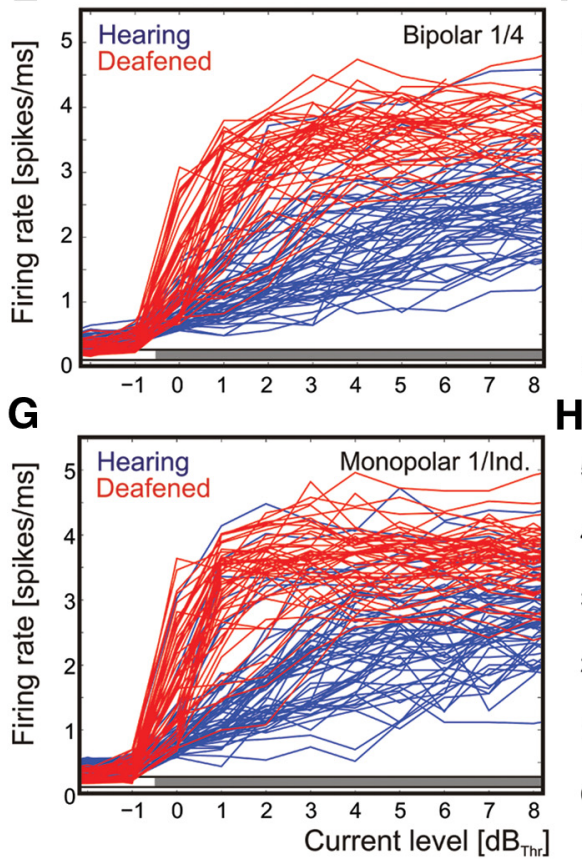

H
B $\quad \mathrm{CF}>9 \mathrm{kHz}$

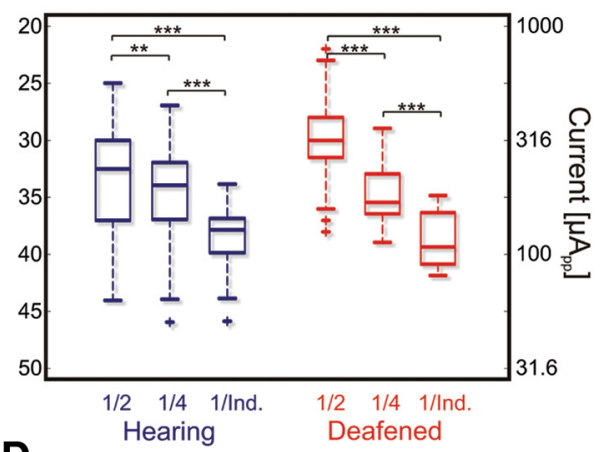

D
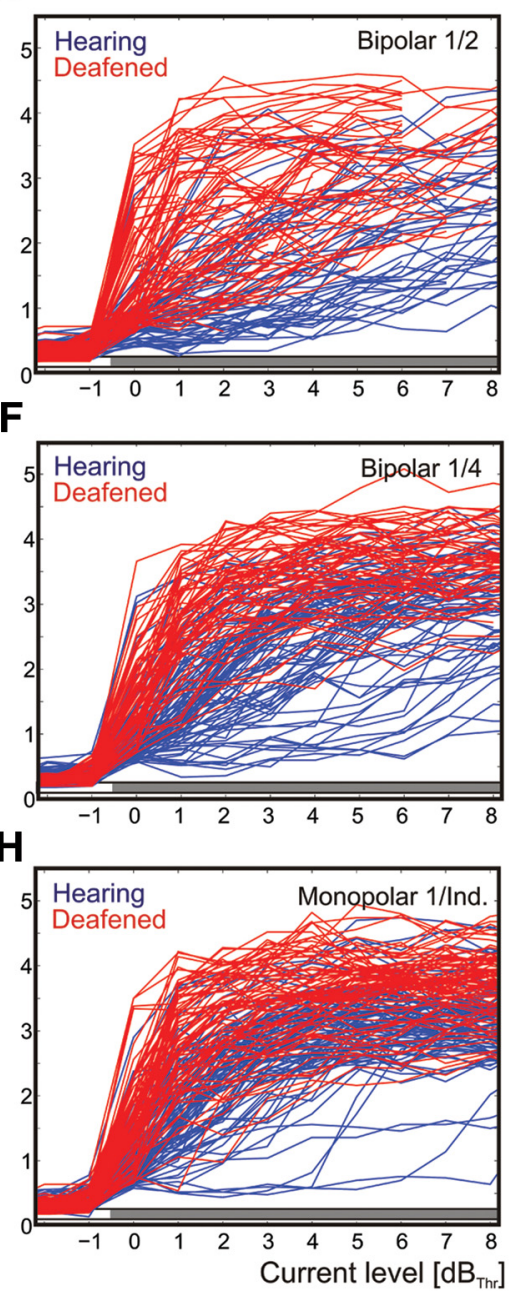

Figure 5. Population data on the effect of current spread, biphasic pulse (100 $\mu$ s/phase). $\boldsymbol{A}$, Threshold levels in all animals plotted separately for low CFs. Blue, Hearing condition. Red, Deafened condition. Increasing current spread decreases response thresholds in the deafened condition, but not in the hearing condition. $\boldsymbol{B}$, Same data as in $\boldsymbol{A}$, but for high CFs. Here, both the hearing and the deafened condition show a decrease in thresholds with increasing current spread. Two-tailed Wilcoxon-Mann-Whitney test, ${ }^{*} \sim 5 \%$ significance level; ${ }^{* *} \sim 1 \%$ significance level; ${ }^{* *} \sim 0.1 \%$ significance level. $\boldsymbol{C}-\boldsymbol{H}$, Rate-level functions pooled from all animals in hearing (blue) and deafened (red) condition, arranged with $\mathrm{dB}$ above hearing threshold. Gray bar above abscissa designates significant difference between hearing and deaf condition at the given current level (two-tailed Wilcoxon-Mann-Whitney test, $\alpha=5 \%$ ). C, E, G, Sites with low CF. Here, in the hearing condition the rate-level functions are less steep and the maximum firing rates lower than in the deafened condition. $\boldsymbol{D}, \boldsymbol{F}$, $\boldsymbol{H}$, Sites with high CF. For these, the rate-level functions are more similar between deafened and hearing conditions, particularly for the broader configurations. However, the absolute firing rate is higher in deafened conditions. In general, the wider the configuration, the smaller the differences in shape of the rate-level functions. $40 \mathrm{~dB}_{\text {att }}$ correspond to $100 \mu A_{p p}$ 
A

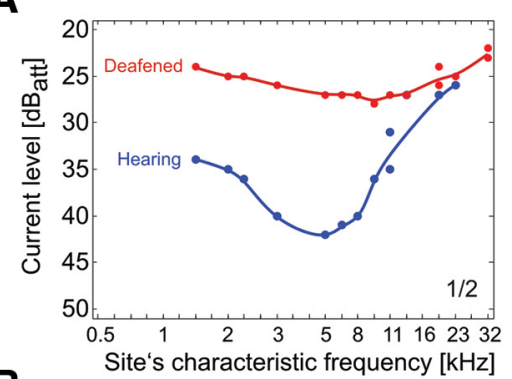

B

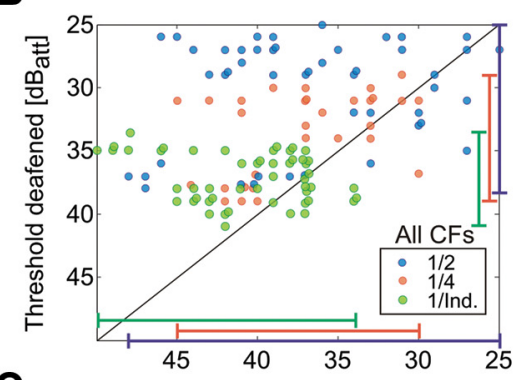

C

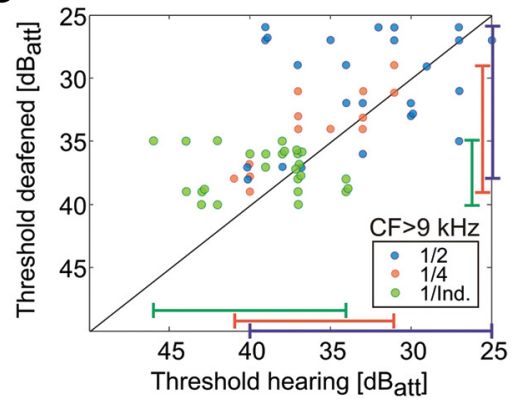

D

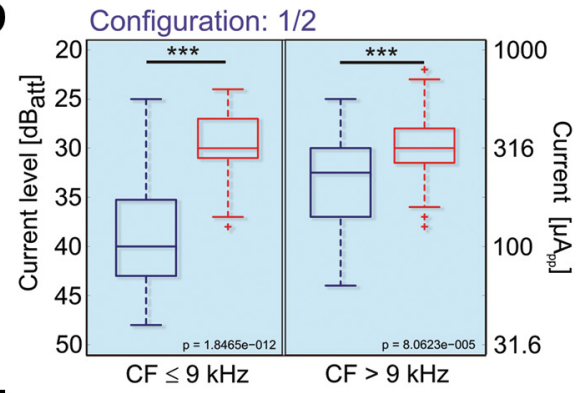

E

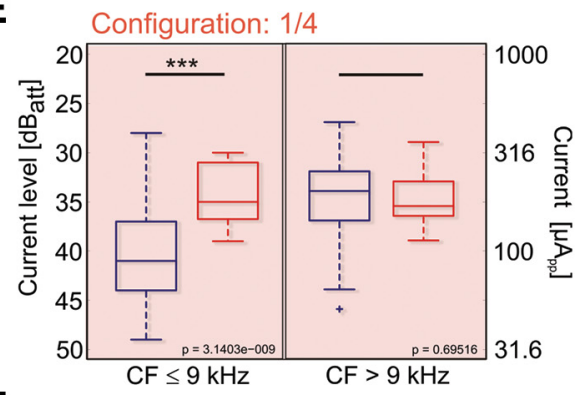

$\mathbf{F}$

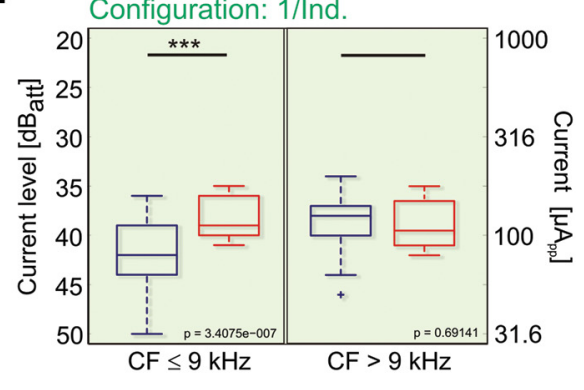

the electrophonic response appeared least distinct from the electroneural response in the monopolar condition.

Finally, when only $\mathrm{CFs}>9 \mathrm{kHz}$ were considered, the differences diminished substantially (Fig. 6C); the data points were grouped more symmetrically along the diagonal. Again, this result is consistent with previous considerations and indicates that electrophonic responses for pulsatile $100 \mu \mathrm{s} /$ phase stimuli are largest in neurons with CFs $\leq 9 \mathrm{kHz}$. To further substantiate this finding, all data recorded in the present study were pooled and compared for the different configurations in hearing and deafened conditions (176 recordings; Fig. $6 D-F$ ). For the narrow bipolar $1 / 2$ configuration (Fig. $6 D$ ), the pooled thresholds were significantly and substantially smaller in hearing animals, both in apical and basal parts of the cochlea $\left(p=1.8 \times 10^{-12}\right.$ for CFs $\leq 9 \mathrm{kHz}$ and $p=8.1 \times 10^{-5}$ for $\mathrm{CFs}>9 \mathrm{kHz}$, two-tailed Wilcoxon-Mann-Whitney test). For the wide bipolar configuration (Fig. 6E), the difference was only significant for the apical cochlea $(p=3.1 \times$ $10^{-9}$ vs $p=0.696$ for CFs $\leq 9 \mathrm{kHz}$ and $\mathrm{CF}>9 \mathrm{kHz}$, respectively; WilcoxonMann-Whitney test). For monopolar configuration (Fig. $6 F$ ), lower threshold in the hearing condition was observed only in the apical part of the cochlea ( $p=$ $\left.3.4 \times 10^{-7}\right)$ but not in the basal cochlea $(p=0.691)$. This is consistent with the interpretation that the apical excitation is due to electrophonic stimulation in hearing animals, and that the characteristics of electrophonic stimulation are most apparent in the more focused stimulation configurations, where differences between electrophonic and electroneuronal thresholds were largest.

From these data it follows that electri-

detail, we selected a small subset of recordings (Fig. $6 B, C$ ) that adhered to two conditions: the threshold for electrical response available for the same site pre-deafening and post-deafening, and responses to all stimulation configurations of electrode 1 available for levels up to $25 \mathrm{~dB}$ (narrow bipolar 1/2, wide bipolar 1/4, and monopolar 1/Ind.). Since, for narrower configurations in some sites, the response threshold could not be reached, the number of measured values is small and differs for the different configurations. Such data for pre- and post-deafening thresholds were plotted in one diagram along the abscissa and ordinate, regardless of the CF of the sites (Fig. 6B). The data confirm that lower thresholds were observed in the hearing condition, with most data points above the diagonal (Fig. $6 B$ ). The range of thresholds appeared largest for narrow bipolar configurations and smallest for the monopolar configuration, but was generally within $15-20 \mathrm{~dB}$, in line with population dynamics reported in previous studies involving deaf ears (Hartmann et al., 1984; van den Honert and Stypulkowski, 1984, 1987), and with consistently larger ranges in the hearing conditions. Monopolar stimulation yielded the smallest differences between hearing and deaf conditions. In this respect cal stimulation of a hearing cochlea activates two different cochlear partitions: one by electrophonic stimulation, located predominantly in the low-frequency cochlear partition, and the other by electroneural stimulation. Electroneural stimulation is possible in the hearing cochlea, but is weaker than in the deaf cochlea.

To finally demonstrate that the site of electrophonic stimulation is related to the temporal properties of the electrical stimulus, we used sinusoidal stimulation of varying frequencies in hearing cochleae (Fig. 7). This allowed us to modify the temporal property of the electrical signal and filter out the electrical artifact from the recorded signal without interference with unit activity. Also, using this stimulation, two excited cochlear spots were apparent, one having properties of electrophonic responses and the other with properties of electroneural responses. The electrophonic low-threshold excitation region shifted correspondingly to the stimulation frequency, whereas the site of the electroneural stimulation was unaffected by such change- only the threshold 
increased with decreasing charge per period of the stimulus. This eventually demonstrates that the location of the electrophonic stimulation in the cochlea is defined by the time function of the electrical stimulus, whereas the electroneural stimulation is independent of it.

Additionally, the thresholds were lowest for stimulation frequencies corresponding to the $\mathrm{CF}$ of the best electroneural response (near $9.5 \mathrm{kHz}$ in the example shown). This confirms the suggestion above that the generator of the electrophonic response must be close $(\sim 1$ octave) to its best threshold and that moving the stimulating electrode closer to this site generates a stronger electrophonic response. This is also consistent with the observation that, in $1 / 2$ configuration and $100 \mu \mathrm{s} /$ phase pulses, the electrophonic threshold at $5 \mathrm{kHz}$ was considerably lower than for 3/4 configurations (Fig. 3).

All sinusoidal stimulations consistently demonstrated the absence of electrophonic peaks above $11-12 \mathrm{kHz}$ stimulation frequency. Although electroneural responses at $9.5 \mathrm{kHz}$ are clearly discernible in Figure 7 , no electrophonic peaks were observed for stimulation $>11-12 \mathrm{kHz}$, despite the fact that electrophonic thresholds are consistently lower than electroneural ones. The most likely reason is that the capacitance of the structures and membranes involved in the electrophonic excitation short-circuits them for such high frequencies. Neuronal membranes probably provide low-pass filtering of the electrical field, preventing electrophonic responses at high stimulation frequencies.

Furthermore, separable peaks were not observed for both modes of stimulations within \pm 1 octave (in the example shown for 6-12 kHz stimulation frequency and electroneural peak at $9.5 \mathrm{kHz}$ ). This indicates that, in such conditions, interactions between the stimulation modes are probable.

\section{Discussion}

The present study demonstrates that atraumatic cochlear implantation largely does not interfere with normal acoustic hearing. It directly shows that electrical stimulation of a normal-hearing cochlea results in two distinct regions of cochlear excitation represented in the inferior colliculus, one dominated by electrophonic stimulation and one by electroneural stimulation. For the first time, the present study dissociates the electrophonic and electroneural responses by manipulating the stimulus conditions, either keeping the place of stimulation fixed while varying the temporal frequency characteristics of the electrical stimulus or keeping the
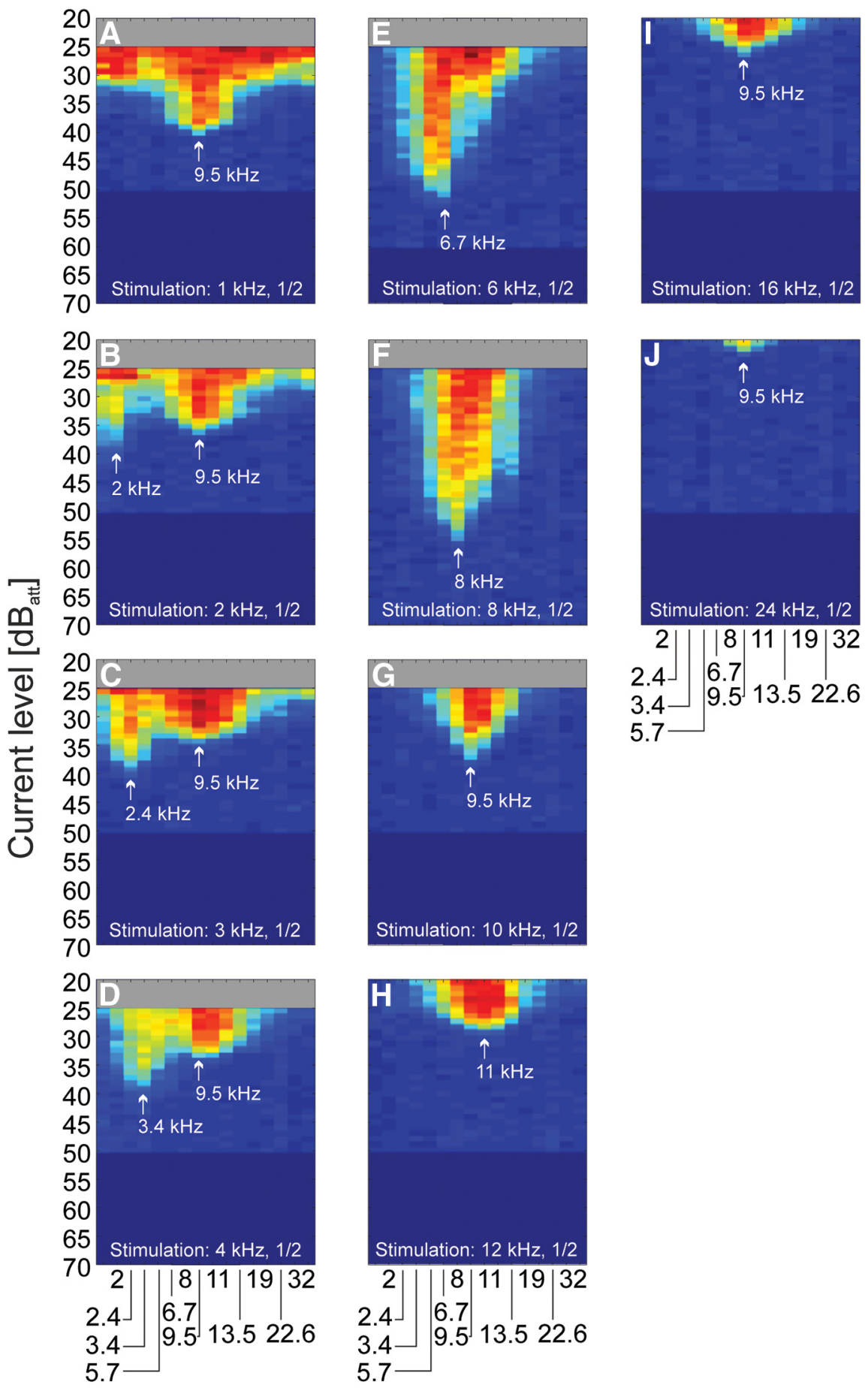

2.4

5.7

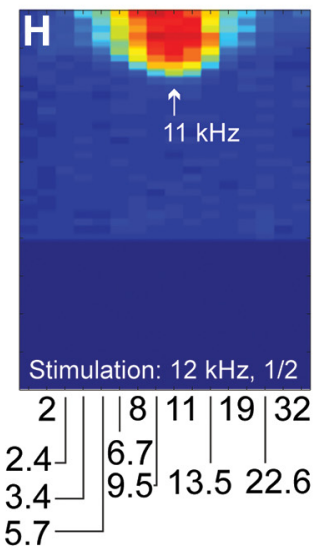

\section{Characteristic frequency $[\mathrm{kHz}]$}

Figure 7. Excitation profiles in a hearing cochlea stimulated with sinusoidal electrical stimulus of varying frequencies. $\boldsymbol{A}$, Stimulation at $1 \mathrm{kHz}$ resulted in one peak of activity with lowest threshold at the site with CF of $9.5 \mathrm{kHz}$, likely corresponding to the position of the active electrodes $1 / 2$. Lowest CF observed in this experiment was $2 \mathrm{kHz}$. $\boldsymbol{B}$, With stimulation at $2 \mathrm{kHz}$, an additional peak at the site with $\mathrm{CF} 2 \mathrm{kHz}$ was observed, with the peak at $9.5 \mathrm{kHz}$ unchanged apart from a threshold increase of $4 \mathrm{~dB}$. The threshold of the $2 \mathrm{kHz}$ peak was lower than the threshold for the site where $\mathrm{CF}=9.5 \mathrm{kHz}$. C, At $3 \mathrm{kHz}$ stimulation, the apical peak moved to the site with a CF of $2.4 \mathrm{kHz}$. D, With $4 \mathrm{kHz}$ stimulation, the apical peak moved to $3.4 \mathrm{kHz}$, with a further increase in threshold of the peak at $9.5 \mathrm{kHz}$. E, At $6 \mathrm{kHz}$ stimulation, the peaks merged and a substantial decrease in threshold was observed, with the best threshold at the site where $\mathrm{CF}=6.7 \mathrm{kHz}$. F, At $8 \mathrm{kHz}$ stimulation, the threshold dropped further, the lowest threshold being observed at the site where $\mathrm{CF}=8 \mathrm{kHz}$. G, At $10 \mathrm{kHz}$, the peak moved to the site with $9.5 \mathrm{kHz} C \mathrm{CF}$, but the threshold increased substantially. $\boldsymbol{H}$, At $12 \mathrm{kHz}$, one peak in the excitation profile was still observed, this time at the site where $\mathrm{CF}=11 \mathrm{kHz}$. I, J, If stimulation frequency increased further, only the peak at $9.5 \mathrm{kHz}$ was observed. $40 \mathrm{~dB}_{\text {att }}$ correspond to $100 \mu \mathrm{A}_{\mathrm{pp}}$. 
temporal characteristics fixed while varying the place of electrical stimulation. The electrophonic response was in the cochlear representation of the dominant frequency component of the electrical stimulus. The electroneural response, on the other hand, was located at the cochlear site close to the stimulating electrode. Deafening eliminated the electrophonic response.

A stimulating contact located closer to the site of the electrophonic response reduced the threshold for electrophonic stimulation. Such an effect was observed when the electrophonic and electroneural peaks were located within $\sim 1$ octave in the cochlear frequency representation.

Previous studies have identified the main properties of electrophonic stimulation, including lower threshold, shallower amplitude-intensity growth, larger dynamic range, and longer response latencies (Moxon, 1971; Lusted and Simmons, 1984, 1988; van den Honert and Stypulkowski, 1984; Miller et al., 2006). Here we used thresholds, rate-intensity functions, and dynamic ranges to characterize the electrophonic responses. Latency differences were not shown, since we recorded activity in the auditory midbrain, many stations beyond the auditory nerve. Latency differences are thus equivocal (even though they were generally in accord with the present conclusions).

The point of strongest electrophonic excitation corresponded to the time function of the electrical stimulus, as suggested in previous studies (McAnally et al., 1997a,b,c). It is probably generated by a traveling wave induced by electrical stimulation, potentially as a consequence of the interaction of the charged scala media (due to endocochlear potential) with the alternating electric field generated by the cochlear implant. Such a mechanism is likely, given that electrical stimulation generates mechanical vibrations of the basilar membrane (Nuttall and Ren, 1995) and leads to generation of otoacoustic emissions (Nuttall et al., 2001). However, indications for direct hair cell stimulation were also observed (see below).

In electrically stimulated hearing cochleae, stimulation has to be considered at low and higher current levels separately. At low current levels, indications of direct hair cell stimulation at the site close to the active electrode were also observed, since the thresholds for narrow bipolar configurations were consistently lower in hearing conditions, including in the high-CF portion of the cochlea. This effect was rather small, consistent with the very rare direct electrical responses of hair cells (the $\delta$ response) observed in the single-fiber recordings (van den Honert and Stypulkowski, 1984). However, the properties of the electrical responses within the high-CF portion in the hearing condition did, in many respects, correspond to the deafened low-CF portion (Figs. 3, 4, 5, 6) and not to the hearing low-CF portion. In the hearing condition, the dynamic range was also smaller in the basal cochlea than in the apical cochlea, suggesting that direct neural stimulation was predominant in the basal cochlea even in the hearing condition. In the hearing condition, living hair cells could provide additional resistance to the current directed toward the scala media and might divert this part of the current toward the modiolus, leading to direct neuronal stimulation at higher current levels and decreasing the dynamic range (Tillein et al., 2015).

At higher current levels, the overall excitation (i.e., firing rate) evoked in the hearing cochlea was less than in the deaf cochlea. This effect is most likely due to the presence of spontaneous activity in the hearing auditory nerve that makes the nerve fibers partially refractory for neuronal stimulation. Given the high spontaneous rates in the auditory nerve, this could prevent electrical excitability in a significant portion of time, reducing the maximum evoked rates.
It is notable that in monopolar stimulation, differences in the electrophonic and electroneural response were less strongly expressed (Figs. 4, 5A, 6C). This was related to the electroneural thresholds being closer to the electrophonic thresholds, and therefore the range of currents with overlap of both mechanisms was larger. The lower electroneural thresholds are probably due to the current path in the monopolar configuration differing from that in the bipolar configuration (for detailed analysis of the current paths, see Kral et al., 1998).

In previous studies, electroacoustic stimulation concentrated mainly on compound action potential recordings that allowed masking phenomena to be observed (Nourski et al., 2005; Stronks et al., 2010, 2013) but could not directly identify the cochlear site where stimulation was performed. Studies involving single auditory nerve recordings confirm some of the above findings (Miller et al., 2009; Tillein et al., 2015), but the small samples of auditory nerve fibers preclude detailed analysis at the population level and unequivocal identification of the stimulated cochlear sites. The present results are in agreement with a previous study on temporal properties of electrical responses in the hearing cochlea (van den Honert and Stypulkowski, 1984). They additionally close important knowledge gaps by demonstrating two separate sites of cochlear excitation with different functional properties and by demonstrating that the extent of excitation in the apical region is weaker than in the basal region. Furthermore, the lower threshold for stimulation in deafened ears than in hearing ears reported previously (Yamane et al., 1981; Miller et al., 2006) was not observed in the present study and is likely the consequence of the use of population measures (such as compound action potentials) or undersampling of the auditory nerve common to the method of single-fiber recordings. In the present study, thresholds of hearing cochleae were consistently (in fact, without exception) lower than those of deafened cochleae.

The present data, in combination with previous studies, implicate two additional new aspects of electrical stimulation in the deaf cochlea. (1) With monopolar stimulation, apical spread of excitation occurs to a significant extent, including those sites that the implant did not reach. (2) When findings on spatial tuning in the cat (Snyder et al., 1990; Kral et al., 1998) are compared with data from the guinea pig (present study; Bierer and Middlebrooks, 2002; Snyder et al., 2004), the tuning of monopolar stimulation appears to depend on the species investigated. In the cat, the single fibers are tuned to the stimulated cochlear position relative to the recorded fiber in the monopolar configuration (the spatial-tuning curves have tips; Kral et al., 1998). In the significantly smaller guinea pig cochlea this is hardly ever the case (present study; Bierer and Middlebrooks, 2002; Snyder et al., 2004). This indicates that, for spatial tuning (current focusing) with electrical stimulation, cochlear size matters. However, a biasing factor is the fact that the position of the implant was likely slightly different in these studies; whereas in the present study the implant was distant to the modiolus, in one cat study (Snyder et al., 2004) the position was close to the modiolus.

Finally, the present study observed that electrophonic and electroneural excitation generated inseparable spots of activity if the activated cochlear regions were closer than an octave to each other. Details of these interactions were not studied here. In previous studies, an absence of distortions was observed at the level of the single auditory fibers, with moderate mutually suppressive phenomena (Tillein et al., 2015), indicating that the interaction was mainly at the level of auditory nerve fibers and not at the level of the organ of Corti. Another previous study in the inferior colliculus noted the dependence on the mutual phase relations of the stimuli, but again did not 
report significant distortions (Vollmer et al., 2010). The present data extend these observations by demonstrating that the interactions depend on cochlear locations of both response types.

\section{Clinical implications}

Although the human electrode-frequency map and the implantation depth differ from present experiments, the findings allow explanation of the benefits of combined electroacoustic stimulation in human subjects. The time function of the electrical pulses used clinically (of the order of 10-50 $\mu$ s) would infer that electrophonic stimulation takes place in the high-frequency portion of the cochlea (which, as a rule, is affected by severe hearing loss). Furthermore, we were unable to identify electrophonic responses in cochlear sites of $>12 \mathrm{kHz}$. The clinically used pulse durations are therefore unlikely to generate electrophonic responses and, therefore, the two stimulation modes probably do not interfere and can complement each other effectively.

\section{References}

Avci E, Nauwelaers T, Lenarz T, Hamacher V, Kral A (2014) Variations in microanatomy of the human cochlea. J Comp Neurol 522:3245-3261. CrossRef Medline

Biedron S, Prescher A, Ilgner J, Westhofen M (2010) The internal dimensions of the cochlear scalae with special reference to cochlear electrode insertion trauma. Otol Neurotol 31:731-737. CrossRef Medline

Bierer JA, Middlebrooks JC (2002) Auditory cortical images of cochlearimplant stimuli: dependence on electrode configuration. J Neurophysiol 87:478-492. Medline

Burghard A, Lenarz T, Kral A, Paasche G (2014) Insertion site and sealing technique affect residual hearing and tissue formation after cochlear implantation. Hear Res 312:21-27. CrossRef Medline

Erixon E, Rask-Andersen H (2013) How to predict cochlear length before cochlear implantation surgery. Acta Otolaryngol 133:1258-1265. CrossRef Medline

Erixon E, Högstorp H, Wadin K, Rask-Andersen H (2009) Variational anatomy of the human cochlea: implications for cochlear implantation. Otol Neurotol 30:14-22. CrossRef Medline

Fraysse B, Macías AR, Sterkers O, Burdo S, Ramsden R, Deguine O, Klenzner T, Lenarz T, Rodriguez MM, Von Wallenberg E, James C (2006) Residual hearing conservation and electroacoustic stimulation with the nucleus 24 contour advance cochlear implant. Otol Neurotol 27:624-633. CrossRef Medline

Greenwood DD (1990) A cochlear frequency-position function for several species-29 years later. J Acoust Soc Am 87:2592-2605. CrossRef Medline

Gstoettner W, Kiefer J, Baumgartner WD, Pok S, Peters S, Adunka O (2004) Hearing preservation in cochlear implantation for electric acoustic stimulation. Acta Otolaryngol 124:348-352. CrossRef Medline

Hartmann R, Topp G, Klinke R (1984) Discharge patterns of cat primary auditory fibers with electrical stimulation of the cochlea. Hear Res 13: 47-62. CrossRef Medline

James C, Albegger K, Battmer R, Burdo S, Deggouj N, Deguine O, Dillier N, Gersdorff M, Laszig R, Lenarz T, Rodriguez MM, Mondain M, Offeciers E, Macías AR, Ramsden R, Sterkers O, Von Wallenberg E, Weber B, Fraysse B (2005) Preservation of residual hearing with cochlear implantation: how and why. Acta Otolaryngol 125:481-491. CrossRef Medline

Kiefer J, Pok M, Adunka O, Stürzebecher E, Baumgartner W, Schmidt M, Tillein J, Ye Q, Gstoettner W (2005) Combined electric and acoustic stimulation of the auditory system: results of a clinical study. Audiol Neurootol 10:134-144. CrossRef Medline

Kral A, Hartmann R, Mortazavi D, Klinke R (1998) Spatial resolution of cochlear implants: the electrical field and excitation of auditory afferents. Hear Res 121:11-28. CrossRef Medline

Lenarz T, Stöver T, Buechner A, Lesinski-Schiedat A, Patrick J, Pesch J (2009) Hearing conservation surgery using the Hybrid-L electrode. Results from the first clinical trial at the Medical University of Hannover. Audiol Neurootol 14 [Suppl 1]:22-31. CrossRef

Lusted HS, Simmons FB (1984) Interaction of cortical evoked potentials to electric and acoustic stimuli. J Acoust Soc Am 76:449-455. CrossRef Medline

Lusted HS, Simmons FB (1988) Comparison of electrophonic and auditory-nerve electroneural responses. J Acoust Soc Am 83:657-661. CrossRef Medline

McAnally KI, Brown M, Clark GM (1997a) Acoustic and electric forward- masking of the auditory nerve compound action potential: evidence for linearity of electro-mechanical transduction. Hear Res 106:137-145. CrossRef Medline

McAnally KI, Brown M, Clark GM (1997b) Comparison of current waveforms for the electrical stimulation of residual low frequency hearing. Acta Otolaryngol 117:831-835. CrossRef Medline

McAnally KI, Brown M, Clark GM (1997c) Estimating mechanical responses to pulsatile electrical stimulation of the cochlea. Hear Res 106: 146-153. CrossRef Medline

Miller CA, Abbas PJ, Robinson BK, Nourski KV, Zhang F, Jeng FC (2006) Electrical excitation of the acoustically sensitive auditory nerve: singlefiber responses to electric pulse trains. J Assoc Res Otolaryngol 7:195-210. CrossRef Medline

Miller CA, Hu N, Zhang F, Robinson BK, Abbas PJ (2008) Changes across time in the temporal responses of auditory nerve fibers stimulated by electric pulse trains. J Assoc Res Otolaryngol 9:122-137. CrossRef Medline

Miller CA, Abbas PJ, Robinson BK, Nourski KV, Zhang F, Jeng FC (2009) Auditory nerve fiber responses to combined acoustic and electric stimulation. J Assoc Res Otolaryngol 10:425-445. CrossRef Medline

Moxon EC (1971) Neural and mechanical responses to electric stimulation of the cat's inner ear. PhD Thesis, Massachusetts Institute of Technology.

Nourski KV, Abbas PJ, Miller CA, Robinson BK, Jeng FC (2005) Effects of acoustic noise on the auditory nerve compound action potentials evoked by electric pulse trains. Hear Res 202:141-153. CrossRef Medline

Nuttall AL, Ren T (1995) Electromotile hearing: evidence from basilar membrane motion and otoacoustic emissions. Hear Res 92:170-177. CrossRef Medline

Nuttall AL, Zheng J, Ren T, de Boer E (2001) Electrically evoked otoacoustic emissions from apical and basal perilymphatic electrode positions in the guinea pig cochlea. Hear Res 152:77-89. CrossRef Medline

Skarzynski H, Lorens A (2010) Electric acoustic stimulation in children. Adv Otorhinolaryngol 67:135-143. CrossRef Medline

Snyder RL, Rebscher SJ, Cao KL, Leake PA, Kelly K (1990) Chronic intracochlear electrical stimulation in the neonatally deafened cat. I: Expansion of central representation. Hear Res 50:7-33. CrossRef Medline

Snyder RL, Bierer JA, Middlebrooks JC (2004) Topographic spread of inferior colliculus activation in response to acoustic and intracochlear electric stimulation. J Assoc Res Otolaryngol 5:305-322. CrossRef Medline

Stronks HC, Versnel H, Prijs VF, Klis SF (2010) Suppression of the acoustically evoked auditory-nerve response by electrical stimulation in the cochlea of the guinea pig. Hear Res 259:64-74. CrossRef Medline

Stronks HC, Versnel H, Prijs VF, de Groot JC, Grolman W, Klis SF (2013) The role of electrophonics in electroacoustic stimulation of the guinea pig cochlea. Otol Neurotol 34:579-587. CrossRef Medline

Tillein J, Hartmann R, Kral A (2015) Electric-acoustic interactions in the hearing cochlea: single fiber recordings. Hear Res 322:112-126. CrossRef Medline

Tsuji J, Liberman MC (1997) Intracellular labeling of auditory nerve fibers in guinea pig: central and peripheral projections. J Comp Neurol 381: 188-202. CrossRef Medline

van den Honert C, Stypulkowski PH (1984) Physiological properties of the electrically stimulated auditory nerve. II. Single fiber recordings. Hear Res 14:225-243. CrossRef Medline

van den Honert C, Stypulkowski PH (1987) Single fiber mapping of spatial excitation patterns in the electrically stimulated auditory nerve. Hear Res 29:195-206. CrossRef Medline

Vollmer M, Hartmann R, Tillein J (2010) Neuronal responses in cat inferior colliculus to combined acoustic and electric stimulation. Adv Otorhinolaryngol 67:61-69. CrossRef Medline

von Ilberg CA, Baumann U, Kiefer J, Tillein J, Adunka OF (2011) Electricacoustic stimulation of the auditory system: a review of the first decade. Audiol Neurootol 16 [Suppl 2]:1-30. CrossRef

Wilson BS (2010) Partial deafness cochlear implantation (PDCI) and electric-acoustic stimulation (EAS) [review]. Cochlear Implants Int 11 [Suppl 1]:56-66. CrossRef

Yamane H, Marsh RR, Potsic WP (1981) Brain stem response evoked by electrical stimulation of the round window of the guinea pig. Otolaryngol Head Neck Surg 89:117-124. Medline

Zhang T, Spahr AJ, Dorman MF (2010) Frequency overlap between electric and acoustic stimulation and speech-perception benefit in patients with combined electric and acoustic stimulation. Ear Hear 31:195-201. CrossRef Medline 